\title{
Chaotropic and Kosmotropic Anions Regulate the Outcome of Enzyme-Mediated Dynamic Combinatorial Libraries of Cyclodextrins in Two Different Ways
}

\author{
Andreas Erichsen, Dennis Larsen and Sophie R. Beeren* \\ Department of Chemistry, Technical University of Denmark, Kongens Lyngby, Denmark
}

We demonstrate how different anions from across the Hofmeister series can influence the behavior of enzyme-mediated dynamic combinatorial libraries of cyclodextrins (CDs). Using cyclodextrin glucanotransferase to catalyze reversible transglycosylation, dynamic mixtures of interconverting cyclodextrins can be formed wherein the relative concentrations of $\alpha-C D, \beta-C D$ and $\gamma-C D$ is determined by their intrinsic stabilities and any

OPEN ACCESS

Edited by:

Anna McConnell,

University of Kiel, Germany

Reviewed by:

Werner M. Nau,

Jacobs University Bremen, Germany

Nicholas White,

Australian National University,

Australia

*Correspondence:

Sophie R. Beeren

sopbee@kemi.dtu.dk

Specialty section: This article was submitted to

Supramolecular Chemistry,

a section of the journa

Frontiers in Chemistry

Received: 07 June 2021

Accepted: 12 July 2021

Published: 03 August 2021

Citation:

Erichsen A, Larsen D and Beeren SR (2021) Chaotropic and Kosmotropic

Anions Regulate the Outcome of

Enzyme-Mediated Dynamic

Combinatorial Libraries of

Cyclodextrins in Two Different Ways.

Front. Chem. 9:721942.

doi: 10.3389/fchem.2021.721942 stabilizing influences of added template (guest) molecules. Here, we find that addition of high concentrations of kosmotropic anions can be used to enhance the effects of added hydrophobic templates, while chaotropic anions can themselves act as templates, causing predictable and significant changes in the cyclodextrin composition due to weak, but specific, binding interactions with $\alpha-C D$.

Keywords: dynamic combinatorial chemistry, supramolecular chemistry, anions, cyclodextrins, cyclodextrin glucanotransferase, templated synthesis, systems chemistry

\section{INTRODUCTION}

Since the groundbreaking work of Franz Hofmeister more than a century ago into how salts affect the solubility of proteins (Hofmeister, 1888), countless studies have repeatedly revealed the Hofmeister series of anions: $\mathrm{F}^{-}, \mathrm{SO}_{4}{ }^{2-}, \mathrm{AcO}^{-}, \mathrm{Cl}^{-}, \mathrm{Br}^{-}, \mathrm{NO}_{3}^{-}, \mathrm{ClO}_{3}^{-}, \mathrm{I}^{-}, \mathrm{ClO}_{4}^{-}$and $\mathrm{SCN}^{-}$. Kosmotropes, such as $\mathrm{F}^{-}$and $\mathrm{SO}_{4}{ }^{2-}$, generally decrease the solubility of proteins and other solutes (salting out), and while the rules governing these phenomena are not fully understood, these ions are said to enhance the hydrophobic effect (Gibb, 2011). Chaotropes, such as $\mathrm{ClO}_{4}{ }^{-}$and $\mathrm{SCN}^{-}$, generally increase the solubility of proteins and other solutes (salting in), cause the denaturation of proteins at high concentrations and diminish the hydrophobic effect. The affinity of chaotropic anions towards hydrophobic surfaces allow them to compete with the interactions between hydrophobic solutes (Gibb and Gibb, 2011). Chaotropic anions form complexes with hosts that have hydrophobic cavities, such as cavitands and cyclodextrins (CDs) (Sullivan et al., 2018). The binding of chaotropic anions to hydrophobic solutes is associated with a certain thermodynamic fingerprint - a favorable enthalpy and an entropic penalty - which has recently been characterized as a generic driving force under the term "the chaotropic effect" by Nau and coworkers (Assaf et al., 2015; Assaf and Nau, 2018). These authors stressed that the chaotropic effect should be distinguished from the classical hydrophobic effect, where the thermodynamic signature is a favorable entropic term. Understanding the different influences of kosmotropes, chaotropes and hydrophobes on selfassembly processes in aqueous solution, both as modulators of solvent effects (Kunz et al., 2004; 


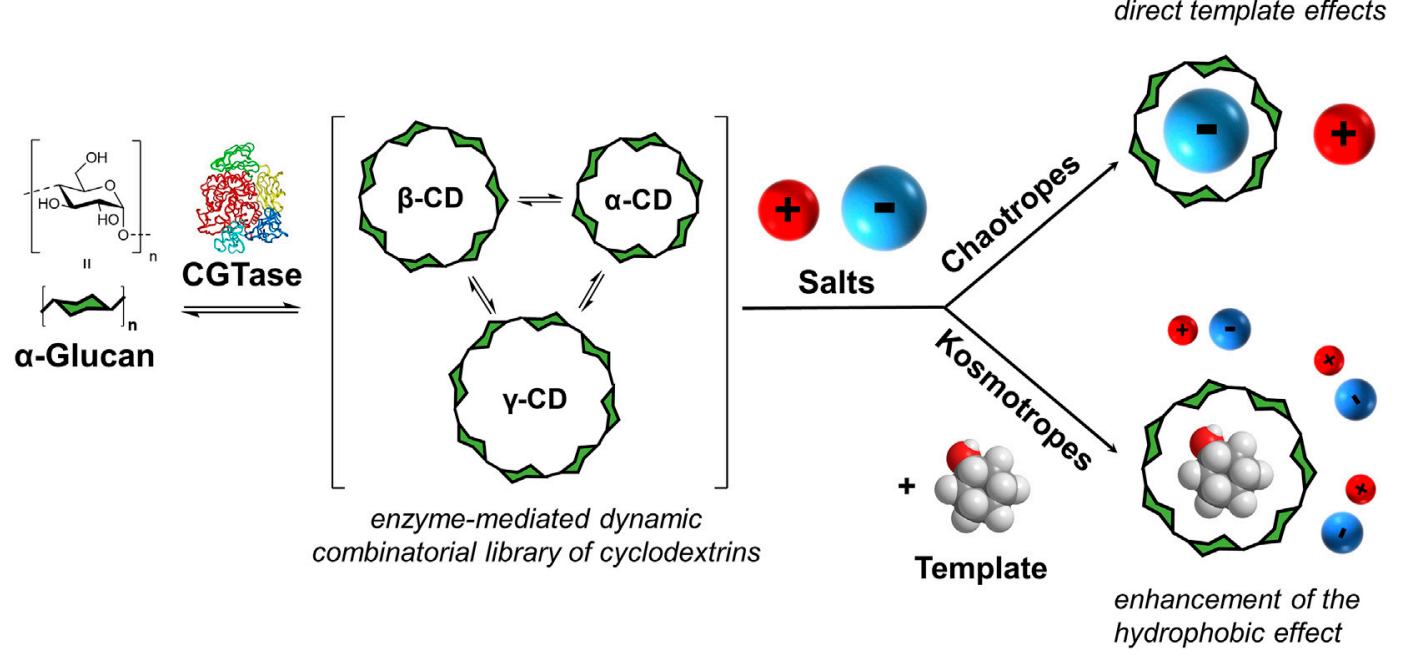

FIGURE 1 | Concept of enzyme-mediated dynamic combinatorial chemistry with $\alpha-1,4$-glucans and the effect of added salts. Cyclodextrin glucanotransferase (CGTase) acts on $a-1,4$-glucans to generate a dynamic mixture of cyclodextrins. Addition of salts leads to either direct template effects (with chaotropic salts) or to the enhancement of the template effect of an added guest (with kosmotropic salts).

Gibb, 2011, Gibb, 2019; van der Vegt and Nayar, 2017) and as recognition motifs (Busschaert et al., 2015; Hillyer and Gibb, 2016; Assaf and Nau, 2018), is key to the successful design of supramolecular systems. In this work, we examine how the interplay between kosmotropic, chaotropic and hydrophobic effects modulates the behavior of an enzyme-mediated dynamic system of cyclodextrins.

Dynamic combinatorial chemistry (DCC) is a powerful method to explore molecular self-assembly and the templated synthesis of complex molecular architectures using reversible bond formation under thermodynamic control (Otto et al., 2002; Corbett et al., 2006; Lehn, 2007; Ponnuswamy et al., 2012; Li et al., 2013). We have previously described how dynamic combinatorial libraries (DCLs) of interconverting cyclodextrins can be generated by employing an enzyme that enables reversible transglycosylation (Larsen and Beeren, 2019, Larsen and Beeren, 2020, Larsen and Beeren, 2021). Cyclodextrins are macrocycles formed from $\alpha$-1,4-linked glucopyranose units. The native cyclodextrins, $\alpha-C D, \beta-C D$ and $\gamma$-CD, with six, seven, and eight glucopyranose units, respectively, exhibit truncated cone-like structures and are widely utilized hosts for the encapsulation of hydrophobic molecules in the foods, pharmaceutical and cosmetics industries (Hedges, 1998; Del Valle, 2004; Sharma and Baldi, 2016). Cyclodextrin glucanotransferase (CGTase) catalyzes both fast, reversible inter- and intramolecular transglycosylation and slow hydrolysis of a (1-4)-glycosidic bonds (Terada et al., 1997; Tewari et al., 1997; Uitdehaag et al., 2002). Exposure of an $\alpha-1,4-$ glucan source to CGTase, therefore, generates a dynamic mixture of linear $\alpha$-1,4-glucans (maltooligosaccharides) and cyclic $\alpha$-1,4glucans (cyclodextrins) (Larsen and Beeren, 2019). As $\alpha-C D$, $\beta$-CD and $\gamma$-CD are intrinsically more stable than their linear counterparts, a complex dynamic system is formed in which $\alpha-C D, \beta-C D$ and $\gamma-C D$ are kinetically trapped and transiently form as the primary products before being eventually converted to glucose.

We previously showed that even though $\alpha-C D, \beta-C D$ and $\gamma$-CD form out-of-equilibrium in this enzyme-mediated dynamic system, they exist in a subsystem that operates under pseudothermodynamic control (Larsen and Beeren, 2019). The distribution of products formed can be controlled by addition of a template that binds selectively to specific cyclodextrins. We were able to produce $\alpha-C D, \beta-C D$ or $\gamma$-CD with $99 \%$ selectivity using sodium dodecyl sulfate, 1-adamantanecarboxylic acid and sodium tetraphenylborate as templates (Larsen and Beeren, 2019, Larsen and Beeren, 2020). While investigating different reaction conditions, it was also found that CGTase could not only tolerate very high concentrations of $\mathrm{NaNO}_{3}$ (up to $7.5 \mathrm{M}$ ) but that the presence of $\mathrm{NaNO}_{3}$ altered the distribution of cyclodextrins in the DCL that was formed. These results encouraged us to explore how the addition of a range of sodium salts in high concentrations would influence the cyclodextrin distribution in our dynamic system. Here, we present how the addition of salts to CGTasemediated DCLs of cyclodextrins can either enhance the template effects of added guests, in the case of kosmotropes, or lead to direct template effects, in the case of chaotropes (Figure 1).

\section{MATERIALS, INSTRUMENTATION AND METHODS}

\section{Materials}

All chemicals and solvents of HPLC (high performance liquid chromatography) grade were obtained from commercial suppliers and used as received. High purity water used both in reactions and chromatographic analysis was obtained using a Merck Millipore Synergy UV water purification system. Colorless Corning CoStar $0.65 \mathrm{ml}$ centrifuge tubes were used for enzymatic 
reactions and sample preparation (dilution and centrifugation), while colorless $2 \mathrm{ml}$ glass vials with PTFE-lined screw-cap septa and $0.2 \mathrm{ml}$ glass inserts were used for short-term sample storage and injection on HPLC equipment. A stock solution of the enzyme CGTase derived from Bacillus macerans was received as a kind gift from Amano Enzyme, Inc., Nagoya, Japan. The stock solution was stored at $5^{\circ} \mathrm{C}$ and used as received.

\section{Instrumentation}

Chromatographic analysis was performed on a Thermo Scientific Dionex Ultimate 3000 HPLC (ultra-high pressure) system equipped with a Waters Acquity UPLC BEH Amide $1.7 \mu \mathrm{m}$ $2.1 \times 150 \mathrm{~mm}$ column maintained at $30^{\circ} \mathrm{C}$, and an autosampler module maintained at $20^{\circ} \mathrm{C}$. Detection was carried out using an Agilent Technologies 1,260 Infinity ELSD (evaporative light scattering detector), operating with the evaporator at $90^{\circ} \mathrm{C}$, nebulizer at $70^{\circ} \mathrm{C}$, and a $\mathrm{N}_{2}$ gas flow of $1.0 \mathrm{~L} / \mathrm{min}$. The ELSD enables the detection of the chromophore-lacking oligosaccharides. Calibration curves from $0.01 \mathrm{mg} / \mathrm{ml}$ to $10 \mathrm{mg} / \mathrm{ml}$ for $\alpha-, \beta$ - and $\gamma$-CD and linear $\alpha-1,4$ glucans up to maltooctaose were used to correct for differences in the ELS detector response for different oligosaccharides. The calibrations were based on masses injected $(0.018-3.66 \mu \mathrm{g})$ and the resulting response curves were fitted to a simple power equation $M=k A^{p}$ (where $M$ is the injected mass of compound, $A$ is the area under the peak in the chromatogram and $k$ and $p$ are fitted parameters) using non-linear curve fitting (in OriginPro 2018b from OriginLab Corp.) See recent paper for details (Larsen and Beeren, 2021). The gradient profile for HPLC runs was a linear gradient from $75 \%$ acetonitrile in water to $55 \%$ acetonitrile in water over $8 \mathrm{~min}$ with a flow rate of $0.6 \mathrm{ml} / \mathrm{min}$. Both eluents contained $0.1 \%$ formic acid by volume.

\section{Enzymatic Reactions and Analysis}

Reaction mixtures with the desired concentrations of salts were prepared by mixing appropriate amounts of two types of stock solutions in buffered water ( $50 \mathrm{mM}$ sodium phosphate at $\mathrm{pH} 7.5$ ): 1) a solution containing $\alpha-C D(10 \mathrm{mg} / \mathrm{ml})$ and various salts $(4.0 \mathrm{M})$; and 2) a solution containing $\alpha-C D(10 \mathrm{mg} / \mathrm{ml})$. In templated experiments, cyclohexanol or cyclohexanecarboxylic acid was dissolved in these resulting mixtures at a concentration of $10 \mathrm{mM}$. For the experiments with a higher concentration of sodium phosphate buffer, a stock solution of $\alpha-C D(10 \mathrm{mg} / \mathrm{ml})$ in $0.45 \mathrm{M}$ sodium phosphate buffer at $\mathrm{pH} 7.5$ was prepared. The starting mixtures containing salt, $\alpha-C D$ and template (if any) in buffer were then aliquoted $(165-365 \mu \mathrm{l})$ into reaction vessels and kept at ambient temperature. All reactions were then initiated by adding CGTase stock solution ( $50 \mu \mathrm{l}$ per $\mathrm{ml}$ of starting mixture) to the starting mixtures followed by thorough mixing. The reactions were then monitored at various time points: Aliquots for analysis $(4-5 \mu \mathrm{l})$ were taken out and rapidly diluted (31 fold) in a $1 \%$ trifluoroacetic acid (TFA) solution in 3:1 acetonitrile/ water with $10 \mathrm{mM}$ ammonium chloride to stop the enzymatic reaction. For experiments with $\mathrm{NaCl}$, aliquots for analysis $(20 \mu \mathrm{l})$ were taken out and rapidly diluted (six fold) in a 1\% TFA solution in water. Samples were then centrifuged (10,000 RPM for $4 \mathrm{~min})$ to prevent column blockage by insoluble species such as enzyme and salts, and the top fractions (leaving behind $20 \mu \mathrm{l}$ ) were then transferred to $2 \mathrm{ml}$ glass vials with $0.2 \mathrm{ml}$ glass inserts, kept at $20^{\circ} \mathrm{C}$ and then injected on the HPLC instrument within $48 \mathrm{~h}$. Injection volumes were $10 \mu \mathrm{l}$ or $2 \mu \mathrm{l}$ (for 31-fold and 6-fold diluted samples, respectively). Peaks in the chromatograms corresponding to $\alpha-C D, \beta-C D$ and $\gamma-C D$ and linear $\alpha-1,4-$ glucans up to maltooctaose were identified by comparison with authentic samples obtained from commercial suppliers.

\section{Simulations of Dynamic Combinatorial Libraries}

Simulations of dynamic combinatorial libraries (DCLs) with and without the anion $\mathrm{SCN}^{-}$were carried out using the DCLSim software developed in the Otto group (Corbett et al., 2004) and kindly made available to us. The program requires input of the concentration of the building block (glucopyranose units in this case), the composition of the oligomers (library members) formed in the DCL ( $\alpha-C D, \beta-C D$ and $\gamma-C D$, with six, seven or eight glucose units in this case), the relative formation constants $K_{\mathrm{f}}$ of the library members (determined from the pseudoequilibrium composition of $\alpha-, \beta-$, and $\gamma$-CD in an untemplated library), the binding constants $\left(K_{\mathrm{a}}\right)$ of each library member to the template $\left(\mathrm{SCN}^{-}\right)$and the concentration of the template. Details about how the relative formation constants $K_{\mathrm{f}}$ of $\alpha-, \beta-$, and $\gamma$-CD were calculated can be found in the Supplementary Material. The binding constants used were obtained from a study carried out by Tokunaga and coworkers, where the authors used ${ }^{1} \mathrm{H}-\mathrm{NMR}$ spectroscopy to determine binding constants between inorganic anions and cyclodextrins (Matsui et al., 1997).

\section{RESULTS AND DISCUSSION}

\section{The Influence of a Series of Anions on Cyclodextrin DCLs}

To explore the influence of anions on CGTase-mediated DCLs of cyclodextrins, we examined a series of DCLs prepared in the presence of different sodium salts at concentrations up to $4 \mathrm{M}$. The following series of anions was investigated, ranked according to the Hofmeister series: $\mathrm{HPO}_{4}{ }^{2-} / \mathrm{H}_{2} \mathrm{PO}_{4}{ }^{-}>\mathrm{Cl}^{-}>\mathrm{NO}_{3}{ }^{-}>\mathrm{Br}^{-}>$ $\mathrm{ClO}_{4}^{-}>\mathrm{SCN}^{-}$. The libraries were prepared by addition of CGTase $(50 \mu \mathrm{l}$ stock solution per $\mathrm{ml}$ reaction mixture) to solutions of $\alpha-C D(10 \mathrm{mg} / \mathrm{ml})$ with the desired sodium salts at various concentrations up to $4 \mathrm{M}$ concentration in phosphate buffer ( $50 \mathrm{mM}, \mathrm{pH} 7.5)$. Despite the lower solubility of sodium phosphates, we chose also to include phosphate buffer in this study albeit at a maximum of $0.45 \mathrm{M}$. The library compositions were monitored as the dynamic system evolved over time using hydrophilic interaction liquid chromatography (HILIC) with an evaporative light scattering detector (ELSD), which enabled the separation and quantification of the chromophore-lacking glucan mixtures. The influence of varying concentrations of different salts on the equilibrium cyclodextrin distribution and the time taken to reach this steady distribution is summarized for all anions tested in Table $\mathbf{1 .}$ 
TABLE 1 | Summary of results (relative CD yield at pseudo-equilibrium and time to pseudo-equilibrium) for CGTase-mediated Dynamic Combinatorial Libraries (DCLs) of cyclodextrins in the presence of different sodium salts.

\begin{tabular}{|c|c|c|c|c|c|c|}
\hline \multirow[t]{2}{*}{ Entry \# } & \multirow[t]{2}{*}{ Salt $^{\mathbf{a}}$} & \multirow[t]{2}{*}{ Salt concentration (M) } & \multirow[t]{2}{*}{$\begin{array}{l}\text { Time to pseudo-equilibrium } \\
\text { (h) }\end{array}$} & \multicolumn{3}{|c|}{$\begin{array}{l}\text { Relative CD yield at pseudo- } \\
\text { equilibrium (\% by weight) }\end{array}$} \\
\hline & & & & $\alpha-C D$ & $\beta-C D$ & $\gamma-C D$ \\
\hline 1 & No salt & - & 1 & 32 & 57 & 11 \\
\hline 2 & $\mathrm{HPO}_{4}^{2-} / \mathrm{H}_{2} \mathrm{PO}_{4}^{-}$ & 0.45 & 1 & 36 & 54 & 10 \\
\hline 3 & $\mathrm{NaCl}$ & 1 & 1 & 37 & 54 & 10 \\
\hline 4 & $\mathrm{NaCl}$ & 2 & 2 & 37 & 54 & 9 \\
\hline 5 & $\mathrm{NaCl}$ & 3 & 2 & 37 & 53 & 9 \\
\hline 6 & $\mathrm{NaCl}$ & 4 & 4 & 40 & 52 & 8 \\
\hline 7 & $\mathrm{NaNO}_{3}$ & 1 & 1 & 48 & 45 & 7 \\
\hline 8 & $\mathrm{NaNO}_{3}$ & 2 & 1.5 & 49 & 45 & 6 \\
\hline 9 & $\mathrm{NaNO}_{3}$ & 3 & 2 & 51 & 43 & 6 \\
\hline 10 & $\mathrm{NaNO}_{3}$ & 4 & 2 & 55 & 40 & 5 \\
\hline 11 & $\mathrm{NaBr}$ & 1 & 1 & 41 & 50 & 8 \\
\hline 12 & $\mathrm{NaBr}$ & 2 & 1.5 & 44 & 49 & 7 \\
\hline 13 & $\mathrm{NaBr}$ & 3 & 2.5 & 48 & 46 & 6 \\
\hline 14 & $\mathrm{NaBr}$ & 4 & 4 & 54 & 40 & 5 \\
\hline 15 & $\mathrm{NaClO}_{4}$ & 1 & 3 & 62 & 36 & 2 \\
\hline 16 & $\mathrm{NaClO}_{4}$ & 2 & 6 & 65 & 34 & 1 \\
\hline 17 & $\mathrm{NaClO}_{4}$ & 3 & d & - & - & - \\
\hline 18 & $\mathrm{NaSCN}$ & 1 & 2 & 72 & 26 & 2 \\
\hline 19 & $\mathrm{NaSCN}$ & 2 & 8 & 75 & 23 & 2 \\
\hline 20 & $\mathrm{NaSCN}$ & 3 & $d$ & - & - & - \\
\hline
\end{tabular}

${ }^{a}$ Conditions: $\alpha-C D(10 \mathrm{mg} / \mathrm{ml})$ in sodium phosphate buffer $(50 \mathrm{mM}, \mathrm{pH} 7.5)$ treated with CGTase at room temperature.

${ }^{b}$ Estimated time (to the nearest half hour) until a steady distribution of CDs was obtained.

${ }^{c}$ Values taken from a single data point after a steady distribution of $C D$ s was obtained. (Instrumental uncertainty of about $\pm 2 \%$ points in the relative $C D$ yields).

${ }^{d}$ Zero or close to zero enzyme activity, presumably due to enzyme denaturation.

Figure 2 shows representative data obtained for DCLs of cyclodextrins prepared in the presence of increasing amounts of $\mathrm{NaBr}$. Figure 2A depicts chromatograms showing the distributions of $\alpha-1,4$-glucan products formed after pseudoequilibrium is obtained (2-6 h) in the absence and presence of different concentrations of $\mathrm{NaBr}$. It is immediately evident that the relative concentration of $\alpha-C D$ increased at the expense of $\beta-C D$ and $\gamma$-CD in the presence of increasing concentrations of $\mathrm{NaBr}$. Amplifications of $\alpha-\mathrm{CD}$ were seen for all the anions tested, but the magnitude of the effect was anion-dependent (Table 1). The evolution of each DCL was monitored over time (Supplementary Figures 1-6). For all DCLs, the CD yield decreased gradually overtime, due to background hydrolysis and the consequent build-up of short linear $\alpha$-1,4-glucan and glucose. For the DCL without salt, a steady distribution of $\alpha-C D, \beta-C D$ and $\gamma$-CD was obtained after approximately one hour, when a pseudo-thermodynamic equilibrium of cyclodextrins was reached. At this point $>90 \%$ of the glucan material was still present as cyclodextrins. With increasing concentrations of $\mathrm{NaBr}$, the evolution of the DCL became slower, and it took up to approximately four hours (with $4 \mathrm{M} \mathrm{NaBr}$ ) to reach a steady distribution of cyclodextrins (Figure 2C). In all cases, addition of anions led to a slower evolution of the dynamic enzymatic system (Supplementary Figures 1-6). With the chaotropic anions $\mathrm{ClO}_{4}{ }^{-}$and $\mathrm{SCN}^{-}$(Table 1, entries 15-20) this retardation was quite significant at 1-2 M concentrations, and at concentrations of $3 \mathrm{M}$ and higher, the activity of the enzyme was zero or close to zero within just $30 \mathrm{~min}$ of being exposed to the salt solutions (Supplementary Figure 8), presumably due to denaturation of the enzyme under these conditions.

The equilibrium cyclodextrin distributions obtained in the presence of different anions at $2 \mathrm{M}$ concentration are summarized in Figure 3. Following a largely systematic trend, the relative yield of a-CD increases upon moving from the most kosmotropic anions $\left(\mathrm{HPO}_{4}{ }^{2-} / \mathrm{H}_{2} \mathrm{PO}_{4}{ }^{-}, \mathrm{Cl}^{-}\right.$, minor changes) to the most chaotropic anions $\left(\mathrm{ClO}_{4}{ }^{-}\right.$, $\mathrm{SCN}^{-}$, large changes). These results suggest that all the tested anions have a specific, albeit weak affinity for a-CD and function as templates in the enzyme-mediated DCL of cyclodextrins. Selected binding constants for $\mathrm{Cl}^{-}, \mathrm{NO}_{3}{ }^{-}, \mathrm{Br}^{-}$, $\mathrm{SCN}^{-}$and $\mathrm{ClO}_{4}{ }^{-}$interacting with $\alpha-\mathrm{CD}, \beta-\mathrm{CD}$ and $\gamma-\mathrm{CD}$ have previously been reported (Table 2 ). These binding constants were determined using a variety of techniques: ${ }^{1} \mathrm{H}-\mathrm{NMR}$ spectroscopy (Matsui et al., 1997), conductance (Wojcik and Rohrbach, 1975), potentiometry (Gelb et al., 1983), spectrophotometry (Buvári and Barcza, 1979), volatilization (Sanemasa et al., 1988) and isothermal titration calorimetry (Sullivan et al., 2018). While the numeric values of the binding constants vary somewhat depending on the method, the trends are certainly clear. In the kosmotropic end of the Hofmeister series, the binding of $\mathrm{Cl}^{-}$to $a-\mathrm{CD}$ was found to be negligible in most cases, which corresponds well with our data, where only minor changes in the cyclodextrin distribution occur upon addition of $\mathrm{Cl}^{-}$(Table 1, entries $3-6)$. The minor increase in the relative yield of $a-C D$, from 32 to $37 \%$, does, however, indicate that there could 


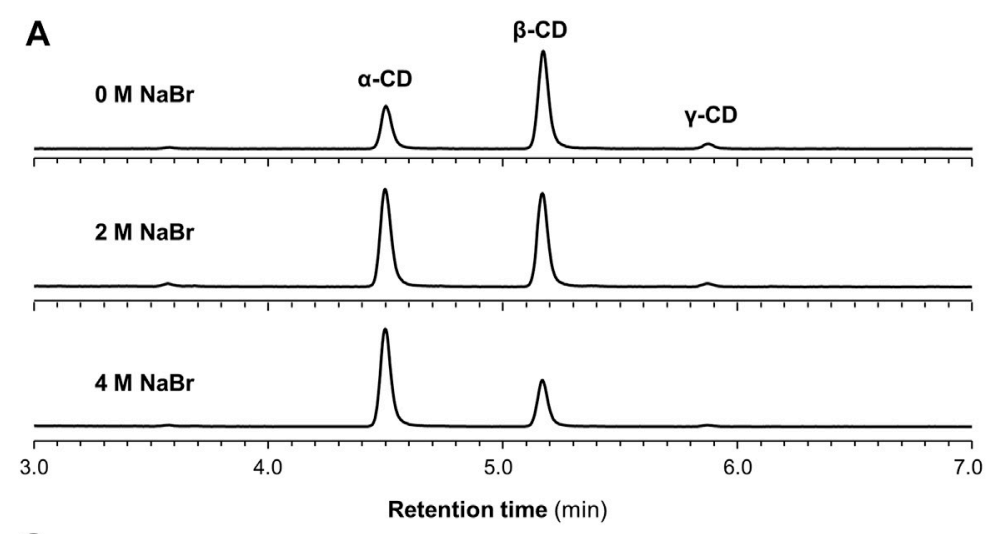

B

C
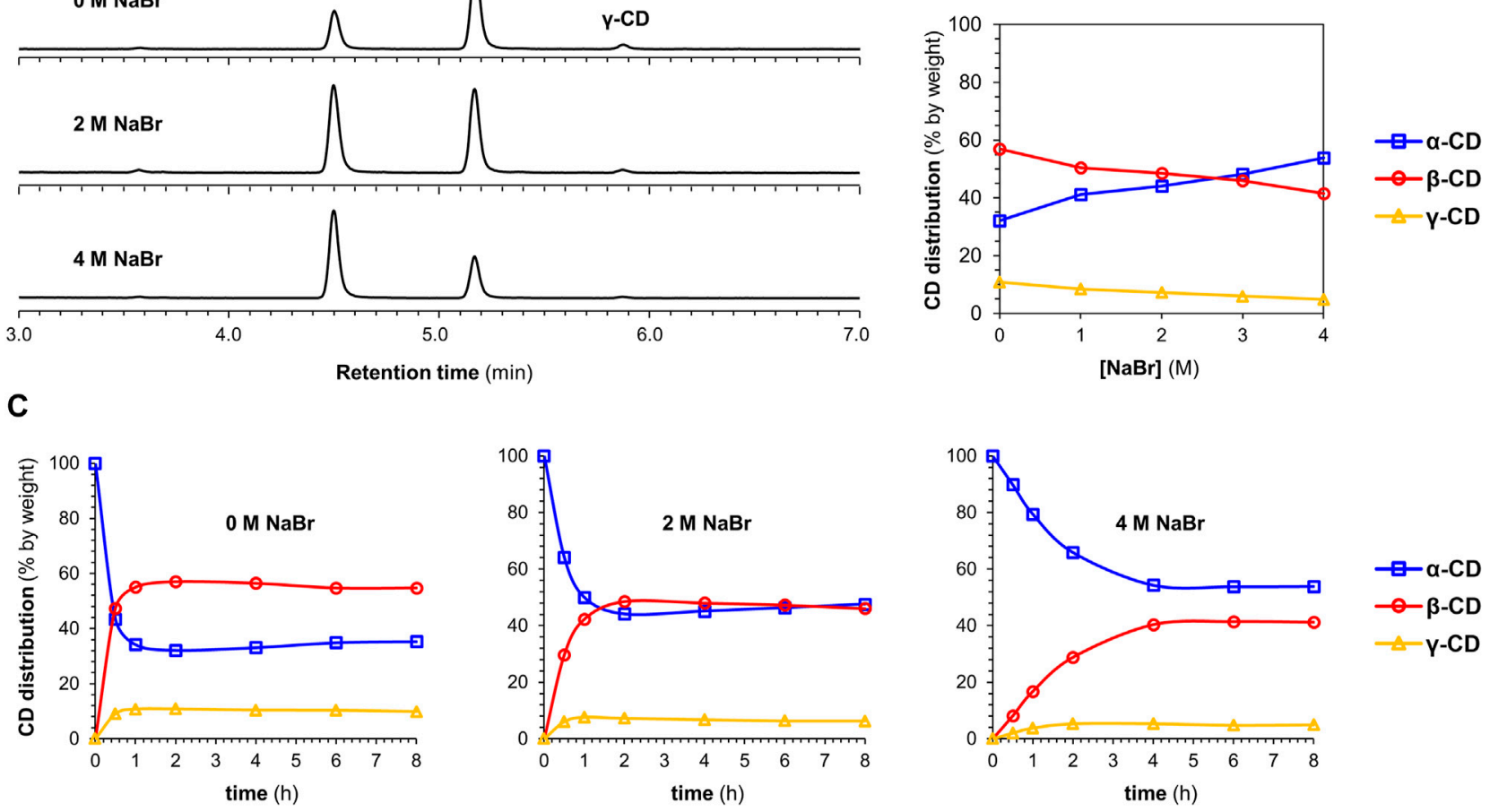

FIGURE 2 | The effect of NaBr on CGTase-mediated DCLs. Conditions: $\alpha-C D(10 \mathrm{mg} / \mathrm{ml})$ in sodium phosphate buffer (50 mM, pH 7.5$)$ treated with CGTase at room temperature (A) Chromatograms (HPLC-ELS) showing the pseudo-equilibrium distribution of CDs produced in the absence or presence of NaBr (2 and $4 \mathrm{M}$ ). The chromatograms show data obtained after $2 \mathrm{~h}(0$ and $2 \mathrm{M} \mathrm{NaBr}$ ) or $6 \mathrm{~h}$ (4 M NaBr) (B) Pseudo-equilibrium distribution of CDs as a function of $\mathrm{NaBr}$ concentration (C) $\mathrm{CD}$ distribution monitored over time in the absence or presence of $\mathrm{NaBr}$ (2 and $4 \mathrm{M}$ ) (lines are included only to guide the eye).

be a very weak binding between $\alpha-\mathrm{CD}$ and $\mathrm{Cl}^{-}$, as found in some cases in the literature (Wojcik and Rohrbach, 1975). Next in the series, both $\mathrm{NO}_{3}{ }^{-}$and $\mathrm{Br}^{-}$bind to $a-\mathrm{CD}$ with small and similar binding constants $\left(1-4 \mathrm{M}^{-1}\right)$, which matches the small but significant amplification of $\alpha$-CD observed with these anions (Table 1, entries 7-14). The chaotropic anions $\mathrm{SCN}^{-}$and $\mathrm{ClO}_{4}{ }^{-}$have significantly higher affinities for a-CD (16-46 $\mathrm{M}^{-1}$ ) and led to much larger changes in the cyclodextrin distribution (Table 1, entries 15-20). The fact that the amplification of $\alpha-\mathrm{CD}$ is larger with $\mathrm{SCN}^{-}$than $\mathrm{ClO}_{4}{ }^{-}$ can be explained by the relatively higher competing affinity of $\mathrm{ClO}_{4}{ }^{-}$for $\beta-\mathrm{CD}$, as the distribution obtained in a DCL is influenced by the binding interaction of the template with all members of a library. It is noteworthy that each of the small anions tested amplified and bound most strongly to $a-C D$, whereas we have previously observed the amplification of larger CDs with 8,9 , and 10 glucopyranose units in the presence of the large superchaotropic anion $\mathrm{B}_{12} \mathrm{I}_{12}{ }^{2-}$ (diameter 11.7 $\AA$ ) (Larsen and Beeren, 2019). There is clearly, thus, a relationship between the size of the anion (Table 2 column 3) and the preferential formation of the $\mathrm{CD}(\mathrm{s})$ with a suitable size cavity. Overall, we found that the addition of anions in high concentrations to the CGTasemediated DCLs of cyclodextrins leads to changes characteristic of template effects, and remarkably, the system remains dynamic even at $2 \mathrm{M}$ concentrations of the denaturing salts $\mathrm{NaSCN}$ and $\mathrm{NaClO}_{4}$.

\section{Simulation to Support Templating Effects of Chaotropes}

To gain further support for our conclusion that chaotropic anions influence the production of specific cyclodextrins in CGTasemediated dynamic systems through direct template effects, we sought to simulate the DCL generated in the presence of increasing concentrations of NaSCN. DCLSim is a software developed in the Otto group (Corbett et al., 2004) that enables the prediction of product distributions in templated DCLs operating under thermodynamic control. To simulate the DCLs, binding constants for the interaction of the template with each library member ( $\alpha-C D, \beta-C D$ and $\gamma$-CD) is required, and this was available for $\mathrm{SCN}^{-}$(Table 2, column $\mathrm{I}$, Matsui et al., 1997). The relative formation constants $K_{\mathrm{f}}$ for $\alpha-C D$, $\beta$-CD and $\gamma$-CD are also needed for the simulation and these could be calculated from the relative concentrations of $\alpha-C D$, $\beta$-CD and $\gamma$-CD generated at equilibrium in the DCL without salt. We simulated DCLs of cyclodextrins with $\mathrm{SCN}^{-}$at 0,1 and $2 \mathrm{M}$ concentrations. The results, summarized in Figure 4, show that the simulations correlate well with the experimental results, supporting the conclusion that chaotropic anions function as 


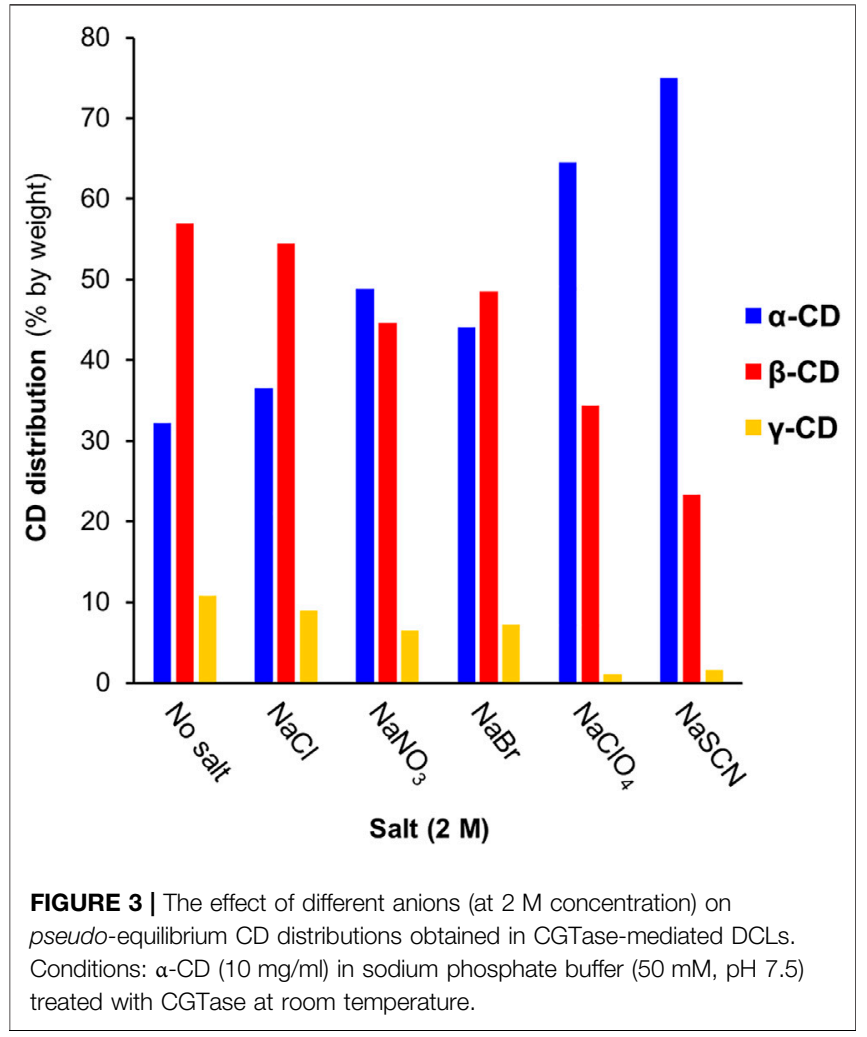

TABLE 2 | Binding constants $\left(K_{a}\right)$ for anions with $\alpha-C D, \beta-C D$ and $\gamma$-CD reported by various authors and the size (diameter, $d$ ) of the anions.

\begin{tabular}{ccccccccc}
\hline Host & Guest & $\boldsymbol{d}(\mathbf{\AA})^{\mathbf{c}}$ & \multicolumn{7}{c}{$\left.\boldsymbol{K}_{\mathbf{a}} \mathbf{( M}^{-\mathbf{1}}\right)^{\mathbf{a}}$} \\
\cline { 4 - 8 } & & & I & II & III & IV & V & VI \\
\hline \multirow{2}{*}{ a-CD } & $\mathrm{Cl}^{-}$ & 3.6 & - & $<1$ & - & $\sim 0$ & 3 & No binding \\
& $\mathrm{NO}_{3}^{-}$ & 4.0 & 1.4 & 1.4 & 2.31 & - & 4 & b \\
& $\mathrm{Br}^{-}$ & 3.9 & 1.6 & 3.5 & 0.96 & - & - & - \\
& $\mathrm{SCN}^{-}$ & 4.3 & 28.4 & 18.7 & 33.5 & - & - & 16 \\
& $\mathrm{ClO}_{4}^{-}$ & 4.8 & 33.0 & 28.9 & 45.8 & - & 35 & 23 \\
\multirow{4}{*}{$\beta-\mathrm{CD}$} & $\mathrm{NO}_{3}^{-}$ & - & - & - & - & 0.2 & - & - \\
& $\mathrm{Br}^{-}$ & - & - & - & 0.45 & 1.1 & - & - \\
& $\mathrm{SCN}^{-}$ & - & 9.2 & 9.9 & 9.2 & 5.7 & - & - \\
& $\mathrm{ClO}_{4}^{-}$ & - & 13.6 & - & - & 9.0 & - & - \\
$\gamma-\mathrm{CD}$ & $\mathrm{SCN}^{-}$ & - & 4.1 & - & - & - & - & -
\end{tabular}

${ }^{a}$ Binding constants for anions (as $\mathrm{Na}^{+}$or $\mathrm{K}^{+}$salts) to $\alpha, \beta$ and $\gamma$-CD measured in $\mathrm{H}_{2} \mathrm{O}$ or $\mathrm{D}_{2} \mathrm{O}$ at $20^{\circ} \mathrm{C}$ or $25^{\circ} \mathrm{C}$ with various techniques: I) ${ }^{1} \mathrm{H}-\mathrm{NMR}$ spectroscopy (Matsui et al., 1997); II) Conductance (Wojcik and Rohrbach, 1975); III) Potentiometry (Gelb et al., 1983); M) Spectrophotometry (Buvári and Barcza, 1979); V Volatilization (Sanemasa et al., 1988); VI) Isothermal titration calorimetry (Sullivan et al., 2018).

${ }^{b}$ Binding too weak to determine a binding constant.

${ }^{c}$ From reference (Marcus, 1994, 1997).

templates in this system, and at high concentrations can strongly influence the product selectivity in CGTase-mediated cyclodextrin synthesis.

\section{Increasing the Template Effect of Hydrophobic Guests by Addition of a Kosmotropic Salt}

As kosmotropic salts can lead to stronger binding between cyclodextrins and hydrophobic guests (Buvári and Barcza,

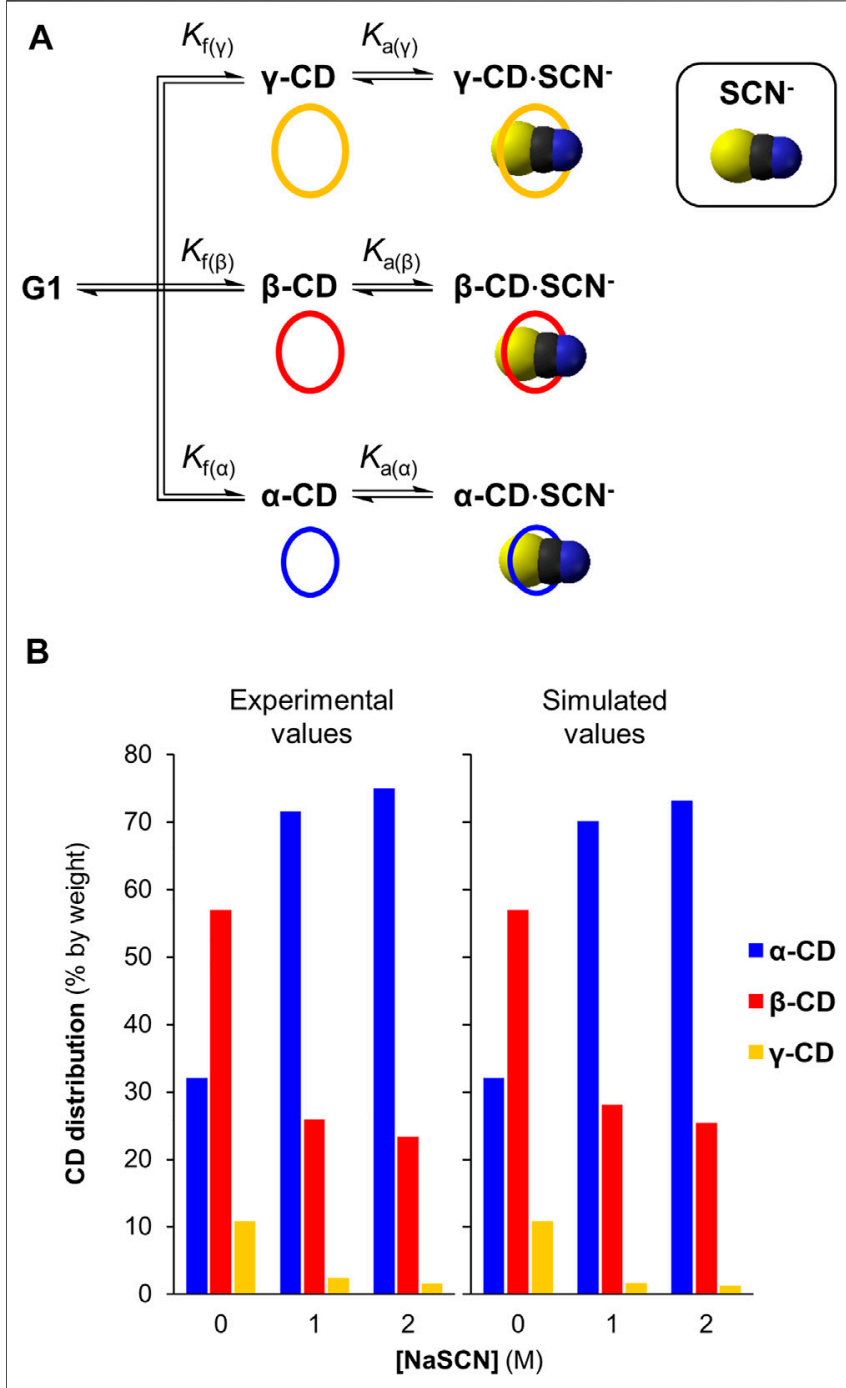

FIGURE 4 | DCLSim simulations of DCLs of cyclodextrins with and without the NaSCN (A) Model employed to simulate DCLs of $\alpha^{-}, \beta-$, and $\gamma$-CD in the presence of $\mathrm{NaSCN}$ (B) Comparison between the simulated and experimentally determined CD distributions with NaSCN (0-2 M).

1979; Holm et al., 2014), we sought to investigate whether we could enhance the template effect of hydrophobic templates in this dynamic cyclodextrin system by using high concentrations of $\mathrm{NaCl}$. For these experiments, we chose to employ cyclohexanol (template 1) and cyclohexanecarboxylate (template 2) as templates, as both guests have a relatively low affinity for $\beta-C D$ in the absence of salts (ca. 700 and ca. $300 \mathrm{M}^{-1}$, respectively) (Gelb and Schwartz, 1989; Rekharsky et al., 1994), thus giving room for a possible improvement in templating effect upon addition of $\mathrm{NaCl}$. A series of CGTase-mediated DCLs were set-up starting from $\alpha-C D(10 \mathrm{mg} / \mathrm{ml})$ with template $(10 \mathrm{mM})$ in phosphate buffer $(50 \mathrm{mM}, \mathrm{pH} 7.5)$ with $0-3 \mathrm{M} \mathrm{NaCl}$ (Supplementary Figure 7). It was found that the addition of $\mathrm{NaCl}$ in increasing concentrations up to $3 \mathrm{M}$ did in fact lead to a moderate increase in the selectivity for $\beta-\mathrm{CD}$ obtained in 


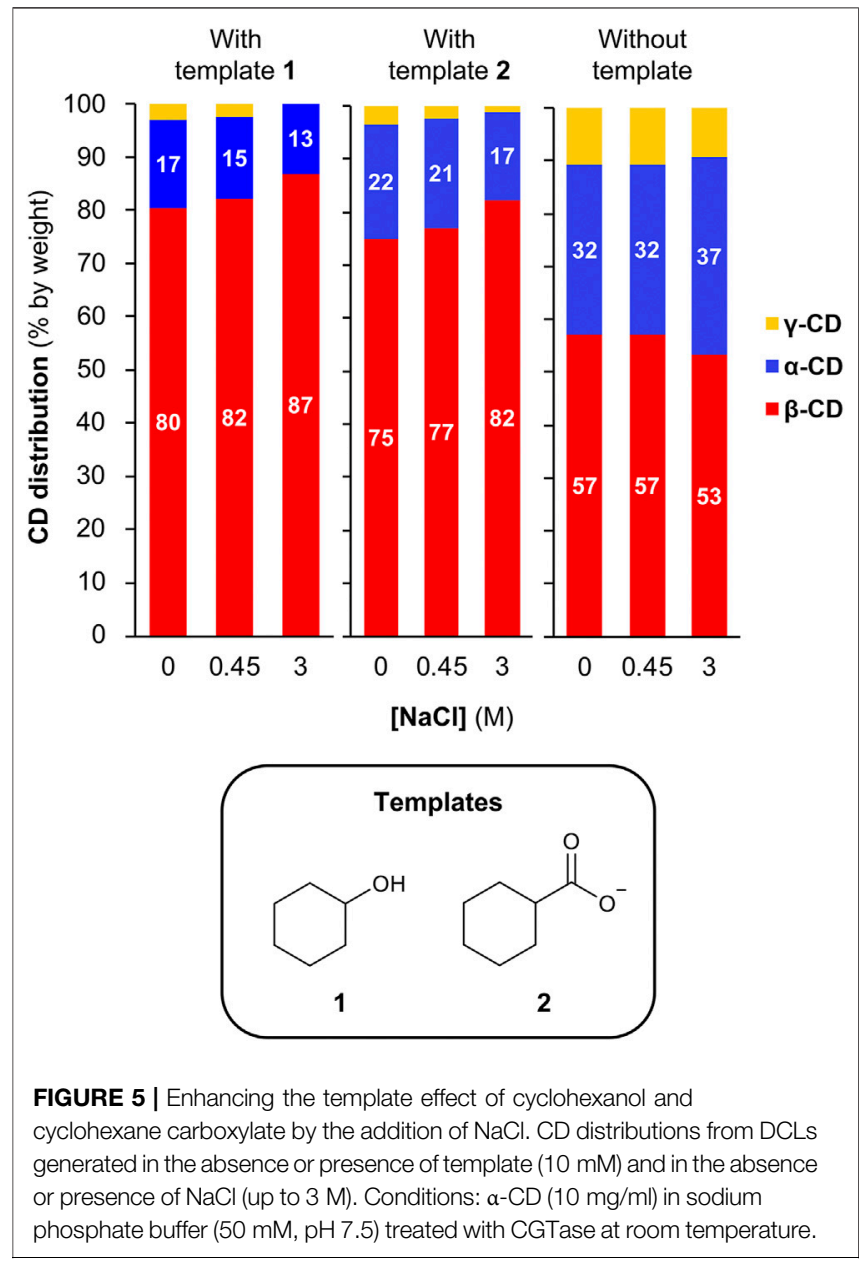

the presence of each template (from 80 to $87 \%$ for template 1 and from 75 to $82 \%$ for template 2) (Figure 5). It is worth noting that increasing the concentration of $\mathrm{NaCl}$ from 0 to $3 \mathrm{M}$ in the absence of template also changes the cyclodextrin distribution, but in the opposite direction, with a decrease in the relative yield of $\beta-C D$ from 57 to $53 \%$, thus counteracting the observed increase in the template effect with 1 and 2. Accordingly, the actual kosmotrope-induced increase in the template effect is potentially larger than the effect observed here.

\section{CONCLUSION}

In this work, we have systematically explored the influence of different anions on the behavior of CGTase-mediated dynamic combinatorial libraries of cyclodextrins and distinguished two key effects. One the one hand, we observed that $\mathrm{NaCl}$ (which lies towards the kosmotropic end of the Hofmeister series) could subtly enhance the templating effects of hydrophobic guest added to the DCLs. On the other hand, we observed direct templating effects due to specific interactions between chaotropes and cyclodextrins. These interactions are very weak $\left(K_{\mathrm{a}}<50 \mathrm{M}^{-1}\right)$, but, when present in high concentrations (2-4 M), chaotropes can, nevertheless, cause significant changes in the distribution of $\alpha-C D, \beta-C D$ and $\gamma$-CD generated. For example, addition of $2 \mathrm{M} \mathrm{NaSCN}$ led to a shift in selectivity from $32 \%$ a-CD to $75 \%$ a-CD. The observed amplifications of $a-C D$ correlated well with reported binding constants, and simulation of DCLs templated with NaSCN matched well to the experimental results, which is further evidence that the observed effects are due to specific anioncyclodextrin binding interactions rather than the global influence of the high salt concentration on the bulk solvent. In fact, this dynamic system potentially provides a new method to identify very weak binding of guests to CDs, which would be very difficult to detect otherwise. Finally, we note that the CGTase used in these experiments was remarkably stable at high salt concentrations. Our study showcases how the interplay between kosmotropes, chaotropes and hydrophobes in dynamic supramolecular systems can be utilized to alter the outcome of these systems in predictable and systematic ways.

\section{DATA AVAILABILITY STATEMENT}

The original contributions presented in the study are included in the article/Supplementary Material, further inquiries can be directed to the corresponding author.

\section{AUTHOR CONTRIBUTIONS}

AE performed the experiments. All authors contributed to the experiment design. DL and SB conceived the concept and supervised the research. AE prepared figures and the original draft of the article. All authors contributed to the preparation and editing of the article.

\section{FUNDING}

The authors are grateful to the Villum Foundation (Grant No. 15482), the Carlsberg Foundation (Grant No. CF19-0510) and the Novo Nordisk Foundation (Grant No. NNF19OC0057672) for financial support for salaries, equipment and running costs.

\section{ACKNOWLEDGMENTS}

The authors are grateful to Amano Enzyme, Inc., Nagoya, Japan, for the kind gift of a stock solution of the enzyme CGTase.

\section{SUPPLEMENTARY MATERIAL}

The Supplementary Material for this article can be found online at: https://www.frontiersin.org/articles/10.3389/fchem.2021.721942/ full\#supplementary-material 


\section{REFERENCES}

Assaf, K. I., and Nau, W. M. (2018). The Chaotropic Effect as an Assembly Motif in Chemistry. Angew. Chem. Int. Ed. 57, 13968-13981. doi:10.1002/anie.201804597

Assaf, K. I., Ural, M. S., Pan, F., Georgiev, T., Simova, S., Rissanen, K., et al. (2015). Water Structure Recovery in Chaotropic Anion Recognition: High-Affinity Binding of Dodecaborate Clusters to $\gamma$-Cyclodextrin. Angew. Chem. Int. Ed. 54, 6852-6856. doi:10.1002/anie.201412485

Busschaert, N., Caltagirone, C., Van Rossom, W., and Gale, P. A. (2015). Applications of Supramolecular Anion Recognition. Chem. Rev. 115, 8038-8155. doi:10.1021/acs.chemrev.5b00099

Buvári, Á., and Barcza, L. (1979). $\beta$-Cyclodextrin Complexes of Different Type with Inorganic Compounds. Inorg. Chim. Acta 33, 179-180. doi:10.1016/S00201693(00)89441-4

Corbett, P. T., Leclaire, J., Vial, L., West, K. R., Wietor, J.-L., Sanders, J. K. M., et al. (2006). Dynamic Combinatorial Chemistry. Chem. Rev. 106, 3652-3711. doi:10.1021/cr020452p

Corbett, P. T., Otto, S., and Sanders, J. K. M. (2004). Correlation between HostGuest Binding and Host Amplification in Simulated Dynamic Combinatorial Libraries. Chem. Eur. J. 10, 3139-3143. doi:10.1002/chem.200400300

Del Valle, E. M. M. (2004). Cyclodextrins and Their Uses: A Review. Process Biochem. 39, 1033-1046. doi:10.1016/S0032-9592(03)00258-9

Gelb, R. I., and Schwartz, L. M. (1989). Complexation of Carboxylic Acids and Anions by Alpha and Beta Cyclodextrins. J. Incl. Phenom. Macrocycl. Chem. 7, 465-476. doi:10.1007/BF01079783

Gelb, R. I., Schwartz, L. M., Radeos, M., and Laufer, D. A. (1983). Cycloamylose Complexation of Inorganic Anions. J. Phys. Chem. 87, 3349-3354. doi:10.1021/ j100240a033

Gibb, B. C. (2019). Hofmeister's Curse. Nat. Chem. 11, 963-965. doi:10.1038/ s41557-019-0355-1

Gibb, B. C. (2011). Supramolecular Assembly and Binding in Aqueous Solution: Useful Tips Regarding the Hofmeister and Hydrophobic Effects. Isr. J. Chem. 51, 798-806. doi:10.1002/ijch.201100058

Gibb, C. L. D., and Gibb, B. C. (2011). Anion Binding to Hydrophobic Concavity Is central to the Salting-In Effects of Hofmeister Chaotropes. J. Am. Chem. Soc. 133, 7344-7347. doi:10.1021/ja202308n

Hedges, A. R. (1998). Industrial Applications of Cyclodextrins. Chem. Rev. 98, 2035-2044. doi:10.1021/cr970014w

Hillyer, M. B., and Gibb, B. C. (2016). Molecular Shape and the Hydrophobic Effect. Annu. Rev. Phys. Chem. 67, 307-329. doi:10.1146/annurev-physchem040215-112316

Hofmeister, F. (1888). Zur Lehre von der Wirkung der Salze. Archiv F. Experiment. Pathol. U. Pharmakol. 25, 1-30. doi:10.1007/BF01838161

Holm, R., Schönbeck, C., Somprasirt, P., Westh, P., and Mu, H. (2014). A Study of Salt Effects on the Complexation between $\beta$-cyclodextrins and Bile Salts Based on the Hofmeister Series. J. Incl. Phenom. Macrocycl. Chem. 80, 243-251. doi:10.1007/s10847-014-0383-9

Kunz, W., Lo Nostro, P., and Ninham, B. W. (2004). The Present State of Affairs with Hofmeister Effects. Curr. Opin. Colloid Interf. Sci. 9, 1-18. doi:10.1016/ j.cocis.2004.05.004

Larsen, D., and Beeren, S. R. (2021). Building up Cyclodextrins from Scratch Templated Enzymatic Synthesis of Cyclodextrins Directly from Maltose. Chem. Commun. 57, 2503-2506. doi:10.1039/d1cc00137j

Larsen, D., and Beeren, S. R. (2019). Enzyme-mediated Dynamic Combinatorial Chemistry Allows Out-Of-Equilibrium Template-Directed Synthesis of Macrocyclic Oligosaccharides. Chem. Sci. 10, 9981-9987. doi:10.1039/ c9sc03983j

Larsen, D., and Beeren, S. R. (2020). Tuning the Outcome of Enzyme-Mediated Dynamic Cyclodextrin Libraries to Enhance Template Effects. Chem. Eur. J. 26, 11032-11038. doi:10.1002/chem.202001076

Lehn, J.-M. (2007). From Supramolecular Chemistry towards Constitutional Dynamic Chemistry and Adaptive Chemistry. Chem. Soc. Rev. 36, 151-160. doi:10.1039/b616752g
Li, J., Nowak, P., and Otto, S. (2013). Dynamic Combinatorial Libraries: From Exploring Molecular Recognition to Systems Chemistry. J. Am. Chem. Soc. 135, 9222-9239. doi:10.1021/ja402586c

Marcus, Y. (1997). Ion Properties. New York: Marcel Dekker.

Marcus, Y. (1994). ViscosityB-coefficients, Structural Entropies and Heat Capacities, and the Effects of Ions on the Structure of Water. J. Solution Chem. 23, 831-848. doi:10.1007/BF00972677

Matsui, Y., Ono, M., and Tokunaga, S. (1997). NMR Spectroscopy of CyclodextrinInorganic Anion Systems. Bcsj 70, 535-541. doi:10.1246/bcsj.70.535

Otto, S., Furlan, R. L. E., and Sanders, J. K. M. (2002). Selection and Amplification of Hosts from Dynamic Combinatorial Libraries of Macrocyclic Disulfides. Science 297, 590-593. doi:10.1126/science.1072361

Ponnuswamy, N., Cougnon, F. B. L., Clough, J. M., Pantos, G. D., and Sanders, J. K. M. (2012). Discovery of an Organic Trefoil Knot. Science 338, 783-785. doi:10.1126/science.1227032

Rekharsky, M. V., Schwarz, F. P., Tewari, Y. B., Goldberg, R. N., Tanaka, M., and Yamashoji, Y. (1994). Thermodynamic and NMR Study of the Interactions of Cyclodextrins with Cyclohexane Derivatives. J. Phys. Chem. 98, 4098-4103. doi:10.1021/j100066a032

Sanemasa, I., Fujiki, M., and Deguchi, T. (1988). A New Method for Determining Cyclodextrin Complex Formation Constants with Electrolytes in Aqueous Medium. Bcsj 61, 2663-2665. doi:10.1246/bcsj.61.2663

Sharma, N., and Baldi, A. (2016). Exploring Versatile Applications of Cyclodextrins: An Overview. Drug Deliv. 23, 729-747. doi:10.3109/ 10717544.2014.938839

Sullivan, M. R., Yao, W., Tang, D., Ashbaugh, H. S., and Gibb, B. C. (2018). The Thermodynamics of Anion Complexation to Nonpolar Pockets. J. Phys. Chem. B 122, 1702-1713. doi:10.1021/acs.jpcb.7b12259

Terada, Y., Yanase, M., Takata, H., Takaha, T., and Okada, S. (1997). Cyclodextrins Are Not the Major Cyclic a-1,4-Glucans Produced by the Initial Action of Cyclodextrin Glucanotransferase on Amylose. J. Biol. Chem. 272, 15729-15733. doi:10.1074/jbc.272.25.15729

Tewari, Y. B., Goldberg, R. N., and Sato, M. (1997). Thermodynamics of the Hydrolysis and Cyclization Reactions of $\alpha-, \beta-$, and $\gamma$-cyclodextrin. Carbohydr. Res. 301, 11-22. doi:10.1016/s0008-6215(97)00073-6

Uitdehaag, J. C. M., van der Veen, B. A., Dijkhuizen, L., and Dijkstra, B. W. (2002). Catalytic Mechanism and Product Specificity of Cyclodextrin Glycosyltransferase, a Prototypical Transglycosylase from the $\alpha$-amylase Family. Enzyme Microb. Tech. 30, 295-304. doi:10.1016/S0141-0229(01) 00498-7

van der Vegt, N. F. A., and Nayar, D. (2017). The Hydrophobic Effect and the Role of Cosolvents. J. Phys. Chem. B 121, 9986-9998. doi:10.1021/ acs.jpcb.7b06453

Wojcik, J. F., and Rohrbach, R. P. (1975). Small Anion Binding to Cycloamylose. Equilibrium Constants. J. Phys. Chem. 79, 2251-2253. doi:10.1021/j100588a010

Conflict of Interest: The authors declare that the research was conducted in the absence of any commercial or financial relationships that could be construed as a potential conflict of interest.

Publisher's Note: All claims expressed in this article are solely those of the authors and do not necessarily represent those of their affiliated organizations, or those of the publisher, the editors and the reviewers. Any product that may be evaluated in this article, or claim that may be made by its manufacturer, is not guaranteed or endorsed by the publisher.

Copyright (c) 2021 Erichsen, Larsen and Beeren. This is an open-access article distributed under the terms of the Creative Commons Attribution License (CC BY). The use, distribution or reproduction in other forums is permitted, provided the original author(s) and the copyright owner(s) are credited and that the original publication in this journal is cited, in accordance with accepted academic practice. No use, distribution or reproduction is permitted which does not comply with these terms. 